\title{
Correction to: Efficacy and Safety of the Newer Multiple Sclerosis Drugs Approved Since 2010
}

\author{
Simon Faissner $^{1}$ (I) $\cdot$ Ralf Gold $^{1}$
}

Published online: 24 May 2018

(C) Springer International Publishing AG, part of Springer Nature 2018

\section{Correction to: CNS Drugs (2018) 32(2):269-287}

https://doi.org/10.1007/s40263-018-0488-6

Page 271, Table 1, "Pivotal trial data and most important drug information": In the 'Dimethyl fumarate' row, 'ARR reduction' column, the DEFINE trial entry, which previously read:

"43\%"

should read:

" $53 \%$ "

The corrected Table 1 is shown on the following page:

The original article can be found online at https://doi.org/10.1007/ s40263-018-0488-6.

Ralf Gold

ralf.gold@rub.de

1 Department of Neurology, St. Josef-Hospital, Ruhr-

University Bochum, Gudrunstr. 56, Bochum 44791, Germany 


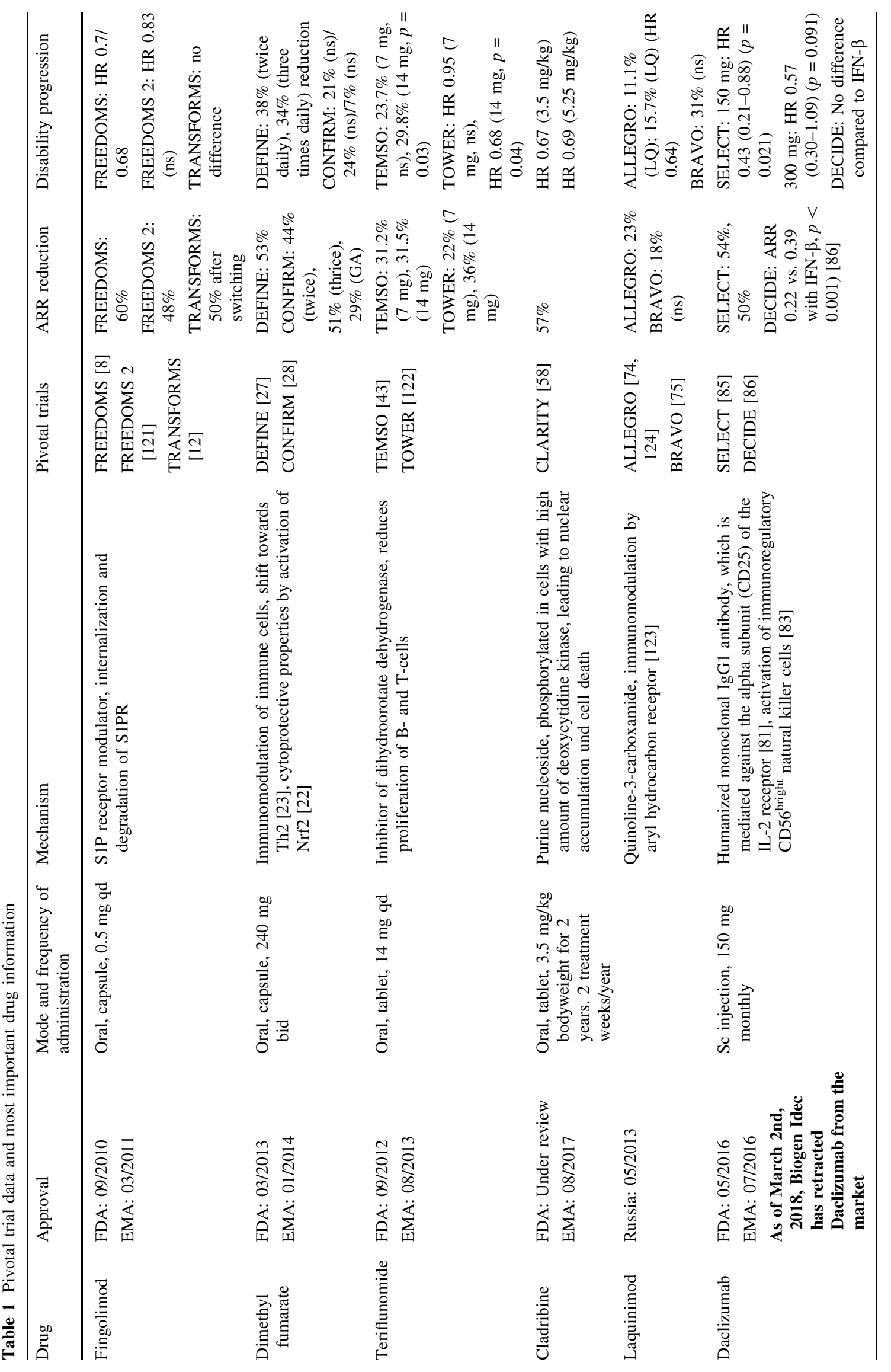




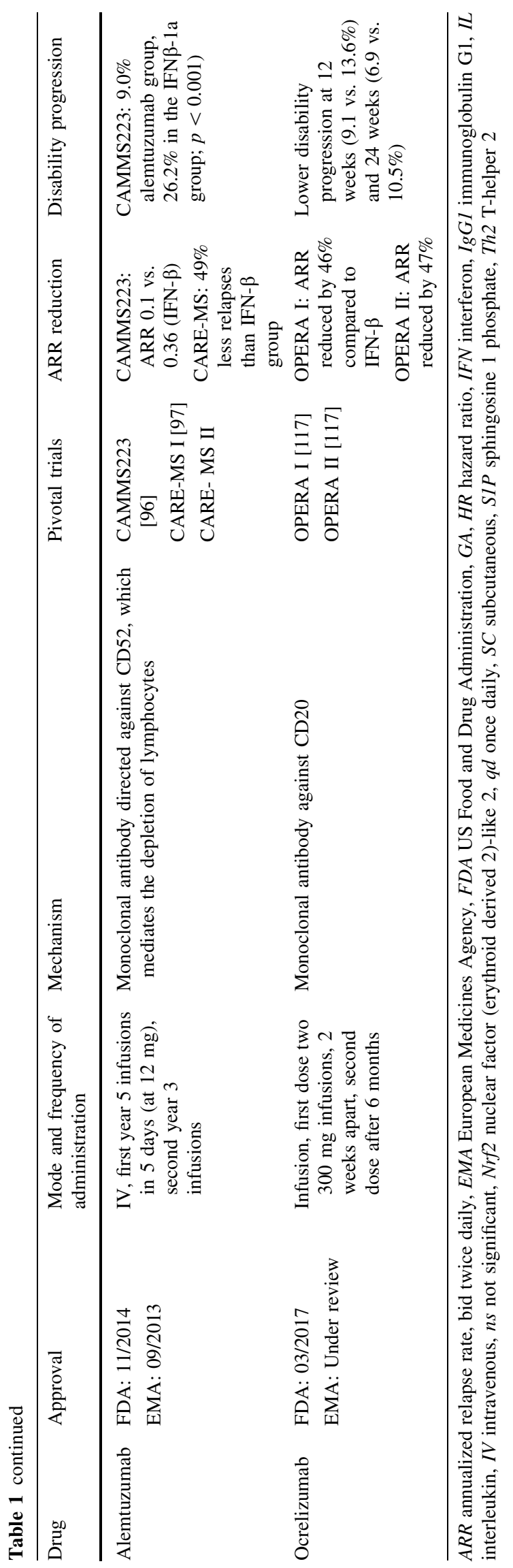

